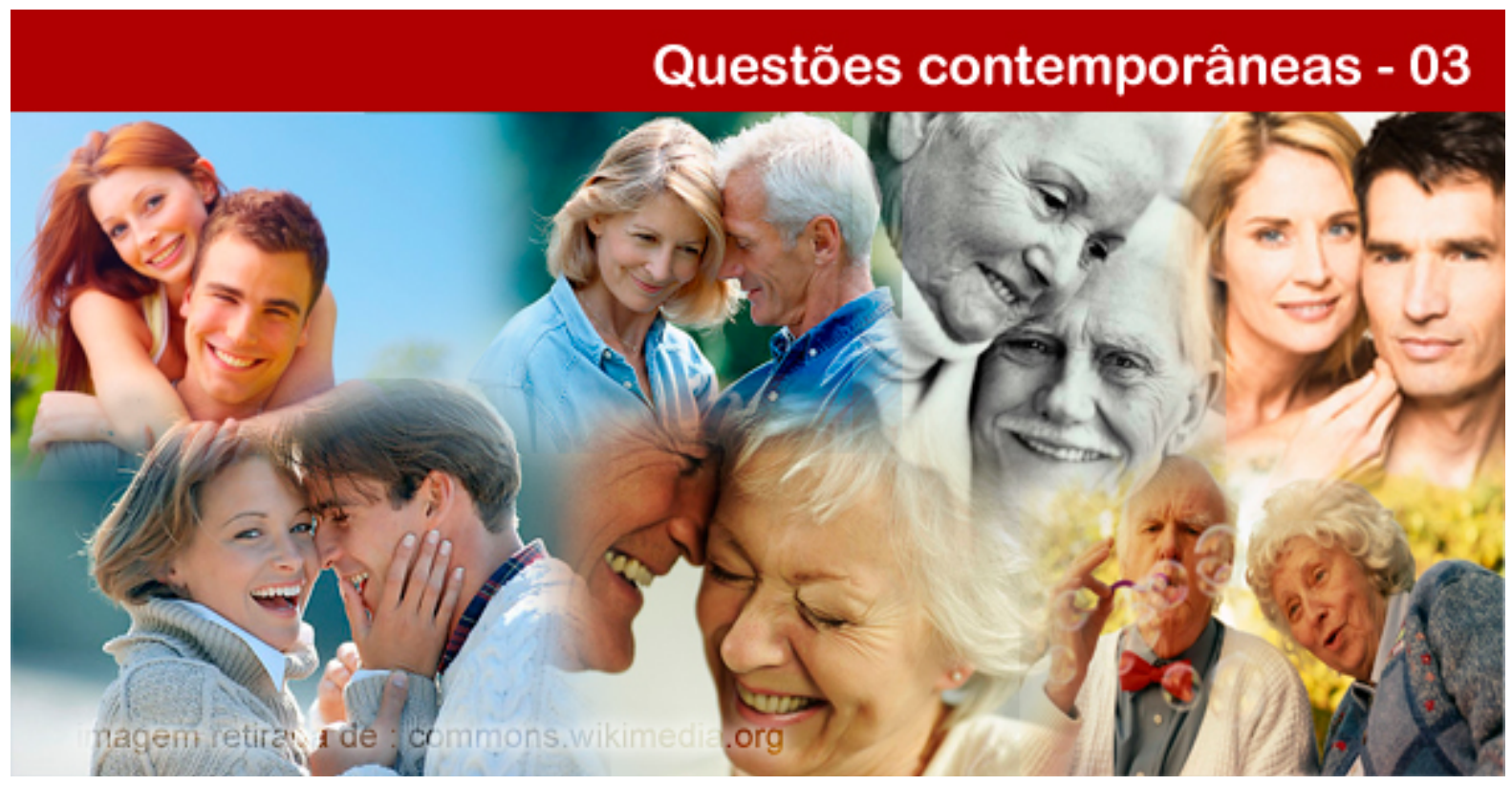

\title{
O PAPEL DA EMPATIA E DA COMUNICAÇÃO ASSERTIVA NA SATISFAÇÃO CONJUGAL EM CASAMENTOS DE LONGA DURAÇÃO
}

\author{
Regina Coeli Tannus Fonseca \\ Psicóloga, graduada pela Faculdade Salesiana Maria Auxiliadora - FSMA. E-mail: \\ tannusfonseca@hormail.com.

\section{Ana Lúcia Novais Carvalho} \\ Psicóloga. Professora adjunta da Universidade Federal Fluminense - UFF - ESR (Campos dos Goytacazes). \\ Doutora em Biologia pela Universidade Estadual do Rio d Janeiro - UERJ.
}

Resumo: A qualidade dos relacionamentos interpessoais tem grande valor para a vida do indivíduo e, quando o assunto é relação conjugal, sua influência é bastante significativa. Pesquisas têm mostrado a importância das habilidades sociais para a qualidade do casamento e sua ação na satisfação conjugal. Esse estudo investiga as relações entre a empatia e a comunicação assertiva, percebidas pelo cônjuge, e a satisfação conjugal. Participaram cinquenta casais, com idade entre 31 e 77 anos, com mais de 10 anos de união. Os participantes preencheram a Escala de Satisfação Conjugal, o Inventário de Habilidades Sociais Conjugais e o Questionário de Empatia Conjugal. Foi observada uma correlação positiva entre a satisfação conjugal e a empatia, sendo esta mais intensa do que a correlação entre a satisfação conjugal e a comunicação assertiva. De acordo com a intensidade da correlação, o presente estudo aponta para a importância da empatia na satisfação conjugal. A comunicação assertiva também tem o seu papel, mas podemos sugerir que o trabalho desta habilidade deve ser precedido por um treinamento da empatia.

Palavras-chave: Satisfação Conjugal. Empatia. Comunicação Assertiva. Habilidades Sociais. Casamento

\section{THE EMPATHY AND ASSERTIVE COMMUNICATION ROLE IN THE MARITAL SATISFACTION IN LONG-TERM MARRIAGES}

Abstract: Interpersonal relationship quality has great value in individual life and when the subject is married couple satisfaction its influence is quite significant. Researches have shown the importance of social skills in marriage quality and their action on conjugal satisfaction. This study investigates the relation between empathy and assertive communication perceived by the spouse and the married couple satisfaction. The participants were fifty couples, aged between 31 and 77 years old, having more than 10 years of marriage. The participants filled the Marital Satisfaction Scale, the Marital Social Skills Inventory and the Marital Empathy Questionnaire. It was observed a positive correlation between marital satisfaction and assertive communication. According to the

\section{POLÊM!CA $\mid$ LABORE (3)}

Polêmica - Revista Eletrônica da Uerj - Rua São Francisco Xavier, 524, $1^{\circ}$ andar bloco D, sl.1001 • Tels.: +55 21 2334-4088 / 4087 • http://www.e-publicacoes.uerj.br/index.php/polemica/index http://www.labore.uerj.br • laboreuerj@yahoo.com.br 
correlation intensity, this study points out the importance of empathy on marital satisfaction. Assertive communication also has its hole, but we can suggest that the role of this ability has to be preceded by some empathy training.

Keywords: Marital Satisfaction. Empathy. Assertive Communication. Social Skills. Marriage.

As configurações familiares vêm passando por mudanças ao longo das últimas décadas, mas para alguns, o casamento continua sendo uma importante realização na vida. Compreende-se que buscar e encontrar alguém, compartilhar a vida e, possivelmente, ter filhos ainda representa uma importante realização em diversas sociedades (FÉRESCARNEIRO, 1998).

Wendling (2007) esclarece que nos casamentos contemporâneos os indivíduos depositam uma grande expectativa em relação ao parceiro, maior idealização do outro e elevada exigência consigo mesmo. Esperando alcançar intimidade, amizade, afeto, realização sexual, companheirismo, cumplicidade e ocasião para o desenvolvimento emocional de modo pleno, o casal necessita constituir trocas e flexibilidade para que seja preservada a individualidade de cada membro. Cria-se, assim, espaço para discutir as variáveis envolvidas no desenvolvimento de um casamento com qualidade.

O tema satisfação conjugal é atual e próprio à modernidade. As variáveis envolvidas neste sentimento vêm sendo levantadas e estudos têm comprovado a importância da satisfação conjugal para a qualidade de vida do casal e para o bem-estar de seus filhos (MOSMANN, WAGNER \& FÉRES-CARNEIRO, 2006).

Dela Coleta (1989) enfatiza que a satisfação conjugal é um conceito subjetivo, onde os cônjuges esperam ter seus desejos e necessidades atendidas e retribuindo ao mesmo tempo ao que seu parceiro espera. Assim, nesse aspecto, a satisfação conjugal é vista como consequência do que o casal espera e não como a realidade do dia a dia do seu casamento.

Desta forma, muitas vezes, a satisfação conjugal não está ligada de maneira direta à ausência de conflito, mas sim, à maneira com que o casal estabelece estratégias para solucioná-los (MOSMANN \& FALCKE, 2011).

Satisfação Conjugal, portanto, é um conceito subjetivo que sugere necessidades e desejos satisfeitos, atendendo de maneira intensa ou não, ao que o outro espera, determinando uma doação recíproca e dificultando uma precisão acerca de sua definição (NORGREN et. al., 2004).

\section{POLÊM!CA $\mid$ LABORE}

Polêmica - Revista Eletrônica da Uerj - Rua São Francisco Xavier, 524, $1^{\circ}$ andar 
Norgren et al. (2004) destacam, ainda, que não é a solidez de um casamento que o transforma em uma relação satisfatória. A durabilidade de um casamento não determina que uma satisfação prevaleça entre os casais, pois diversos fatores podem contribuir para que as pessoas mantenham a relação conjugal, como o medo da separação e suas crenças religiosas. Por outro lado, do mesmo modo que a relação vai se modificando conforme os anos passam, o nível de satisfação também se modifica.

Assim, é importante avaliar as diferentes maneiras de se viver um relacionamento conjugal de maior duração. Segundo os autores, esses casais já conviveram com diversas mudanças em seu casamento, como a necessidade de se adaptarem ao nascimento dos filhos e até mesmo ao medo da solidão quando esses saem de casa. Todas essas situações exigem novos ajustes dos casais. Sendo assim, o que se percebe é que muitas vezes alguns cônjuges sentem dificuldade em superar e se adaptar a essas mudanças inevitáveis de um casamento, enquanto outros casais, naturalmente, tentam vencer tais transformações, construindo um dia a dia de relações satisfatórias (NORGREN et al., 2004).

Figueredo (2005) aponta que, entre as mais diferentes variáveis encontradas na literatura que interferem na determinação da satisfação conjugal, as habilidades sociais têm se destacado pela sua importância na qualidade das relações interpessoais. Conforme Del Prette et al. (2008), as habilidades sociais estabelecem importante ponto de atenção das pessoas que lidam com relacionamento conjugal, não só em pesquisas nessa área, como também nos procedimentos terapêuticos e programas preventivos, pois elas podem ser consideradas como um fator efetivo na qualidade do relacionamento entre as pessoas.

O conceito de habilidades sociais aglomera diferentes condutas, tais como: saber colocar e receber críticas positivas a respeito de comportamentos emitidos; exprimir desejos ou negar-se a satisfazê-los, quando expressados por outrem; manifestar emoções; emitir posicionamentos idiossincráticos sobre algum tema, mesmo que não seja compartilhado pelo interlocutor e, ainda, fazer referência de desaprovação quanto ao comportamento do outro. Essas habilidades são necessárias na interação dos indivíduos, abrangendo, inclusive, o relacionamento conjugal (DEL PRETTE \& DEL PRETTE, 2001).

Conforme Lucca (2004), o indivíduo que tem um comportamento social adequado é considerado um autoreforçador com uma boa autoestima e autoeficácia, facilitando com isso sua maneira de enfrentar as dificuldades e acontecimentos desgastantes. Segundo Vicente,

\section{POLÊM!CA $\mid$ LABORE}


Mendes e Pessoa (2009), as habilidades sociais exercem um papel preventivo na redução dos problemas psicológicos, de agressividade, depressão, e também nos problemas conjugais.

Em resumo, Del Prette e Del Prette (1999) denominam habilidades sociais ao repertório de comportamentos utilizados pelo indivíduo para lidar de uma maneira apropriada com as demandas das circunstâncias interpessoais. Para os autores, diferentes classes e subclasses determinam o conjunto de habilidades sociais indispensáveis para o bom relacionamento social, dentre elas destacamos nesse estudo a habilidade de comunicação assertiva e a habilidade empática.

As habilidades assertivas, de acordo com Del Prette e Del Prette (2001), formam uma classe onde estão certos comportamentos relacionados a manifestar opinião, concordar, discordar; fazer, aceitar e recusar pedidos; constituir relacionamento afetivo e sexual; expressar raiva, encerrar relacionamento, entre outros. É relevante destacar, que esses comportamentos são importantes para que a relação do casal seja de igual para igual, onde os membros exponham suas opiniões e necessidades, equilibrando, desse modo, o relacionamento do casal.

Destacamos ainda nos comportamentos assertivos o importante gesto de desculpar-se, que conforme explica os autores, significa reconhecer seus erros, desfazendo os malentendidos, procurando acabar com os ressentimentos e superando os conflitos no relacionamento. Apesar de não ser uma tarefa emocionalmente fácil de ser executada, é importante para o estabelecimento de uma relação com maior qualidade. (DEL PRETTE \& DEL PRETTE, 2001).

Cada pessoa é capaz de escolher o seu modo de agir de acordo com a situação, podendo desenvolver respostas assertivas, não assertivas ou agressivas, fundamentadas na sua ansiedade. Se analisarmos cada circunstância chegaremos à conclusão de que, no comportamento assertivo, os objetivos de ambas as partes, emissor e receptor, serão atingidos e contribui para o aumento da autoapreciação de seu emissor, além de expressar honestidade. Já a reação não assertiva o prejudicado será o emissor que, inibindo seus sentimentos, não conseguirá atingir seus objetivos, podendo se associar ainda à ansiedade e a uma baixa estima. O comportamento agressivo fere e humilha o receptor e, apesar de atingir os objetivos, contribui para transgredir o direito do outro e desrespeitá-lo gerando conflitos interpessoais e contrarreação quase automática (ALBERTI EMMONS, 1978).

\section{POLÊM!CA $\mid$ LABORE}


Essas classes de comportamentos podem ocorrer em vários contextos e com diversos interlocutores, não sendo diferente no relacionamento conjugal. Compreendemos que a comunicação assertiva se apresenta com primordial importância para a melhoria e satisfação do casal (VILLA \& DEL PRETTE, 2012).

Conforme Elias e Brito (2007), quando marido e mulher se relacionam de forma assertiva, promovem melhoria no seu desempenho diante de possíveis desacordos e, como consequência, surgem soluções adequadas dos problemas, satisfação com seus comportamentos, reforçando a si mesmo e aceitação das particularidades dos demais, inclusive do seu cônjuge.

Corroborando com essas afirmações, Villa (2005) enfatiza que aumentando a assertividade, o casal expressa melhor seus sentimentos e opiniões, tendo a possibilidade de construir relacionamentos mais sinceros e recíprocos.

Apesar de o amor ser a grande motivação para o casamento muitas vezes não é a sua falta que leva ao término de um relacionamento, mas sim a dificuldade de um melhor entendimento entre o casal. Assim, merece destaque o papel de uma comunicação assertiva em uma união amorosa, pois à medida que ela acontece, a maneira como um parceiro se comunica interfere na resposta do outro. Então, uma comunicação clara e assertiva contribui para que as interpretações entre o casal sejam autênticas e não provoquem possíveis distorções (FIGUEREDO, 2005).

Conforme Falcone (1999), no cotidiano das pessoas, incluindo também o contexto conjugal, conseguir expressar assertivamente seus desejos, sentimentos e dificuldades facilita a solução dos problemas interpessoais com o cônjuge, aumentando o senso de autoestima e autoeficácia, melhorando a qualidade do relacionamento, aumentando a tranquilidade e satisfação.

Também a empatia tem grande relevância em diferentes contextos de interação social e no casamento não poderia ser diferente. A ausência desta habilidade possibilitaria a ocorrência de muitos conflitos e pesquisas atestam que a habilidade empática é uma das habilidades sociais que tornam as pessoas mais satisfeitas em suas relações conjugais (FIGUEREDO, 2005).

Como retrata Villa (2005), a ausência da habilidade empática nos momentos das divergências e a dificuldade de adotar a perspectiva do outro parecem fazer parte da rotina dos casais que estão em crise.

\section{POLÊM!CA $\mid$ LABORE}


De acordo com Malamut (2009), a empatia é um fator fundamental para que se possa ter um relacionamento conjugal satisfatório. A autora afirma que muitos estudos assinalam que a habilidade de ouvir e compreender, demonstrando empatia quando o outro enfrenta alguma dificuldade, estabelece um dos importantes fatores para um relacionamento feliz, pois à medida que se sente ouvido e compreendido o esposo ou a esposa se sente mais seguro e valorizado.

A habilidade empática, tão importante no relacionamento conjugal, é definida como "a capacidade de compreender e sentir o que alguém pensa e sente em uma situação de demanda afetiva, comunicando-lhe adequadamente tal compreensão e sentimento" (DEL PRETTE \& DEL PRETTE, 2001, p.86).

Falcone et al. (2008, p.323), definindo em outras palavras, atestam que a empatia "é a capacidade de compreender de forma acurada, bem como de compartilhar ou considerar sentimentos, necessidades e perspectivas de alguém expressando esse entendimento de tal maneira que a outra pessoa se sinta compreendida e validada.”.

Corroborando, Dattilio (2011, p. 150) afirma que a empatia estabelece "um prérequisito para a intimidade e para o diálogo positivo” e, se por um lado provoca relacionamentos mais gratificantes e estruturados, a ausência da capacidade empática está relacionada a conflitos conjugais e divórcios. Procurar se colocar no lugar do outro, compreendendo sua maneira de ser e sentir, é um treino que deve ser praticado para que crises e conflitos sejam superados no relacionamento do casal.

Desse modo, Villa (2005) observou, em sua experiência clínica, que muitos casos de separação dos casais ou a busca de apoio psicoterapêutico acontecem em função de dificuldades de um ou ambos os cônjuges, quanto à empatia ou outra habilidade interpessoal.

Assim, o presente estudo visa avaliar o papel das habilidades assertiva e empática na satisfação conjugal em casamentos de longa duração. Esperamos que a satisfação conjugal se correlacione de maneira positiva com o comportamento assertivo e empático.

\section{Objetivo}

Avaliar o papel da empatia e da comunicação assertiva, percebidas pelo cônjuge, na satisfação conjugal, em casais de longa duração.

\section{Metodologia}

\section{POLÊM!CA $\mid$ LABORE}

Polêmica - Revista Eletrônica da Uerj - Rua São Francisco Xavier, 524, $1^{\circ}$ andar bloco D, sl.1001 • Tels.: +55 $212334-4088$ / 4087 • http://www.e-publicacoes.uerj.br/index.php/polemica/index http://www.labore.uerj.br • laboreuerj@yahoo.com.br 
A amostra foi composta por 50 casais, 100 participantes, com idade mínima de 31 anos e máxima de 77 anos. Todos eram moradores da cidade de Macaé, na Região Norte do Estado do Rio de Janeiro. Para participar do estudo, o tempo mínimo de casamento exigido foi de 10 anos.

Os instrumentos utilizados foram:

- $\quad$ o Termo de Consentimento Livre e Esclarecido (TCLE);

- a Escala de Satisfação Conjugal (ESC), que é um instrumento de autoinforme, traduzido e validado no Brasil por Dela Coleta (1989). Esta escala é composta por três subescalas que medem os aspectos emocionais (SEC), a interação conjugal (SIC) e os aspectos estruturais (SRC) da relação conjugal;

- $\quad$ O Inventário de Habilidades Sociais Conjugais (IHSC, Del Prette \& Del Prette, 2012), composta por cinco fatores: F1 Expressividade/empatia; F2 Autoafirmação assertiva; F3 Autocontrole reativo; F4 Autocontrole proativo; F5 Conversação assertiva;

- $\quad$ O Questionário de Empatia Conjugal (QEC) que avalia os componentes cognitivo (CCoE), afetivo (CAE) e comportamental (CCE) da empatia (Falcone et al., 2008).

\section{Resultados}

Os dados de cada casal foram inseridos em planilha de Excel. Toda a análise estatística foi feita utilizando o software estatístico SPSS - Statistical Package for the Social Sciences (versão 20).

As primeiras análises realizadas foram para obtenção dos dados descritivos da amostra.

Para cada instrumento foi realizado o cálculo da consistência interna. Após a verificação deste dado, foram obtidas as médias e os desvios-padrão para os escores de cada instrumento, permitindo a análise comparativa entre os gêneros, sendo este cálculo feito utilizando-se o Teste T de Student (Teste T). Posteriormente, foi verificada, através do Teste de Correlação de Pearson, a correlação existente entre o fator total da Escala de Satisfação Conjugal com os fatores 1 (Expressividade/Empatia), 2 (Autoafirmação assertiva) e 5 (Conversação assertiva) do Inventário de Habilidades Sociais Conjugais e com o fator total do Questionário de Empatia Conjugal.

\section{POLÊM!CA $\mid$ LABORE}




\section{Dados Descritivos da Amostra}

Os casais entrevistados tinham, no mínimo, 11 anos de casados e, no máximo, 51 anos de casamento, constituindo uma média de 25,68 anos de casados (dp = 10,86). Sobre a presença de filhos, 4 casais declararam não ter filhos e, considerando todos os participantes, 97 (97\%) estavam no primeiro casamento, enquanto que 3 (3\%) viviam o segundo.

Quanto à escolaridade, a maioria dos participantes tinha nível superior (77\%), enquanto que 23 (23\%), ensino médio.

\section{Consistência Interna}

Para obter a consistência interna de cada instrumento, foi calculado o coeficiente Alfa de Cronbach. A Escala de Satisfação Conjugal obteve Alfa de 0,89, o Inventário de Habilidades Sociais Conjugais obteve Alfa de 0,82 e o Questionário de Empatia Conjugal, Alfa de 0,92. Concluímos que os instrumentos apresentaram boa confiabilidade para a amostra estudada, possibilitando a continuação das análises estatísticas.

\section{Diferenças entre os sexos}

\section{Escala de Satisfação Conjugal}

Na Escala de Satisfação Conjugal (ESC) não encontramos diferenças estatisticamente significativas entre os sujeitos, considerando o sexo, conforme podemos verificar na Tabela 1.

Tabela - 1: Comparação, por sexo, nos fatores da Escala de Satisfação Conjugal

\begin{tabular}{llllll}
\hline ESC & Sexo & Média & $\begin{array}{l}\text { Desvio } \\
\text { padrão }\end{array}$ & $t$ & $p$ \\
\hline SEC & Masculino & 11,44 & 2,48 & 1,463 & 0,147 \\
& Feminino & 10,70 & 2,58 & & \\
\hline SIC & Masculino & 25,34 & 4,19 & 1,188 & 0,238 \\
& Feminino & 24,34 & 4,23 & & \\
\hline SRC & Masculino & 22,36 & 3,78 & 0,790 & 0,064 \\
& Feminino & 20,92 & 3,91 & & \\
\hline FT & Masculino & 118,28 & 17,27 & 1,843 & 0,068
\end{tabular}

\section{POLÊM!CA $\mid$ LABORE}




\section{Feminino $\quad 111,92 \quad 17,25$}

ESC - Escala de Satisfação Conjugal; SEC - Satisfação com aspectos emocionais do conjugue; SIC - Satisfação com a interação conjugal; SRC - Satisfação com a forma de organização e de estabelecimento e cumprimento de regras; FT - Fator Total

$* \mathrm{p} \leq 0,05 ; * * \mathrm{p}=0,001 ; * * * \mathrm{p}<0,001$

\section{Inventário de habilidades sociais conjugais}

Na presente amostra, no fator total, homens relatam que as suas esposas apresentam um repertório mediano de habilidades sociais conjugais (percentil 30), enquanto que as mulheres declararam repertório abaixo da média (percentil 20) para os seus esposos, mas esta diferença não é estatisticamente significativa. Analisando os fatores de interesse neste estudo, homens e mulheres declararam desempenho dentro da média de seus cônjuges nos fatores F1 (Expressividade/Empatia), F2 (Autoafirmação Assertiva) e F5 (Conversação Assertiva). Cabe destaque para o fato de haver diferença estatisticamente significativa no relato dos esposos e esposas em F5 (p = 0,05), ou seja, conversação assertiva. Os homens, nesta amostra, relataram uma maior habilidade de suas esposas para expressarem seu ponto de vista, defendendo os seus direitos, respeitando as diferenças e o direito do outro (Tabela 2).

Tabela - 2: Comparação, por sexo, nos fatores do Inventário de Habilidades Sociais Conjugais

\begin{tabular}{lllllll}
\hline IHSC & Sexo & Média & $\begin{array}{l}\text { Desvio } \\
\text { padrão }\end{array}$ & Percentil & $t$ & $p$ \\
& & & & & \\
\hline F1 & Masculino & 21,69 & 6,60 & 30 & $-0,701$ & 0,485 \\
& Feminino & 22,53 & 6,65 & 30 & & \\
\hline F2 & Masculino & 24,80 & 6,06 & 50 & 1,015 & 0,313 \\
& Feminino & 23,63 & 5,25 & 30 & & \\
\hline F3 & Masculino & 9,84 & 3,43 & 25 & $-1,854$ & 0,067 \\
& Feminino & 11,08 & 3,21 & 55 & & \\
\hline F4 & Masculino & 6,08 & 2,84 & 30 & $-1,011$ & 0,314 \\
& Feminino & 6,69 & 3,14 & 45 & & \\
\hline F5 & Masculino & 11,73 & 2,60 & 50 & 1,955 & $* 0,053$ \\
& Feminino & 10,61 & 3,06 & 25 & & \\
\hline FT & Masculino & 81,90 & 16,18 & 30 & $-0,216$ & 0,829 \\
& Feminino & 82,59 & 15,56 & 20 & & \\
\hline
\end{tabular}

\section{POLÊM!CA $\mid$ LABORE}

Polêmica - Revista Eletrônica da Uerj - Rua São Francisco Xavier, 524, $1^{\circ}$ andar bloco D, sl.1001 • Tels.: +55 $212334-4088$ / 4087 • http://www.e-publicacoes.uerj.br/index.php/polemica/index http://www.labore.uerj.br • laboreuerj@yahoo.com.br 
IHSC - Inventário de Habilidades Sociais Conjugais; F1 - Expressividade/Empatia; F2 - Autoafirmação assertiva; F3 - Autocontrole reativo; F4 - Autocontrole proativo; F5 - Conversação assertiva; FT - Fator Total. $* \mathrm{p} \leq 0,05 ; * * \mathrm{p}=0,001 ; * * * \mathrm{p}<0,001$

\section{Questionário de empatia conjugal}

No instrumento de empatia conjugal, no fator total, não há diferença no desempenho dos cônjuges. No entanto, quando analisamos cada fator, verificamos que, no fator CAE (componente afetivo da empatia), os homens relataram melhor desempenho de suas esposas nesta habilidade, sendo esta diferença estatisticamente significativa $(\mathrm{p}<0,001)$ (Tabela 3).

Tabela - 3: Comparação, por sexo, nos fatores do Questionário de Empatia Conjugal

\begin{tabular}{llllll}
\hline QEC & Sexo & Média & $\begin{array}{l}\text { Desvio } \\
\text { padrão }\end{array}$ & $t$ & $p$ \\
\hline CCE & Masculino & 51,67 & 10,74 & 0,000 & 1,000 \\
& Feminino & 51,67 & 9,40 & & \\
\hline CCoE & Masculino & 31,61 & 6,16 & 0,193 & 0,848 \\
& Feminino & 31,39 & 5,36 & & \\
\hline CAE & Masculino & 13,51 & 1,82 & 2,894 & $* * 0,005$ \\
& Feminino & 12,49 & 1,67 & & \\
\hline FT & Masculino & 96,80 & 17,43 & 0,378 & 0,706 \\
& Feminino & 95,55 & 15,06 & & \\
\hline
\end{tabular}

QEC - Questionário de Empatia Conjugal; CCE - Componente Comportamental da Empatia; CCoE Componente Cognitivo da Empatia; CAE - Componente Afetivo da Empatia; FT - Fator Total.

$* \mathrm{p} \leq 0,05 ; * * \mathrm{p} \leq 0,001 ; * * * \mathrm{p} \leq 0,001$

\section{Correlação entre as medidas}

Para a análise da correlação entre os instrumentos, foi utilizado o cálculo da correlação de Pearson, extraindo apenas os dados importantes para este estudo. Assim, foram analisadas as seguintes correlações, procurando identificar aquelas estatisticamente expressivas e importantes, conforme descrito por Dancey e Reidy (2013).

- $\quad$ Escore total da ESC e os Fatores 1, 2 e 5 do Inventário de Habilidades Sociais Conjugais;

- $\quad$ Escore total da ESC e o Escore total do QEC.

\section{POLÊM!CA $\mid$ LABORE}


Considerando a presente amostra, observa-se correlação entre as medidas selecionadas, conforme podemos observar na Figura 1.

A- Diagrama de dispersão mostrando a correlação entre o escore total do IHSC e o escore total da ESC ( $\mathrm{n}=100 ; \mathrm{r}=0,696 ; \mathrm{p}<0001)$.

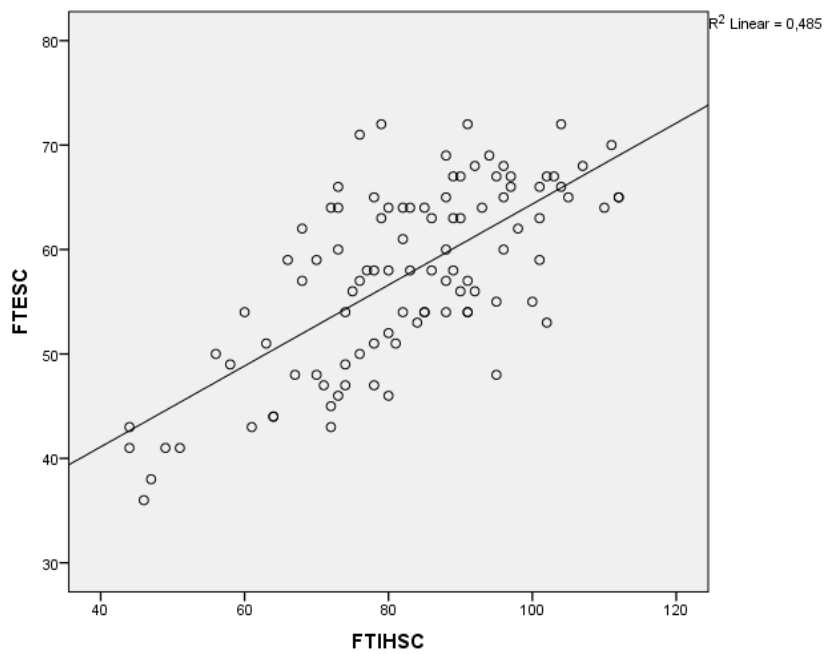

B- Diagrama de dispersão mostrando a correlação entre o F1 do IHSC e o escore total da ESC $(\mathrm{n}=100 ; \mathrm{r}=0,581 ; \mathrm{p}<0,001)$

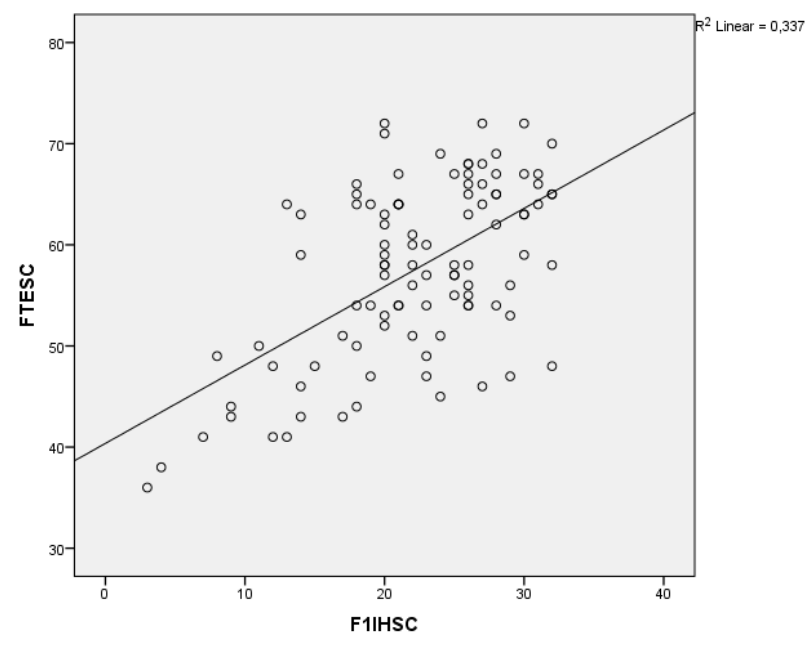

C- Diagrama de dispersão mostrando a correlação entre o F2 do IHSC e o escore total da ESC (n=100; $\mathrm{r}=0,356 ; \mathrm{p}<0001)$

\section{POLÊM!CA $\mid$ LABORE}




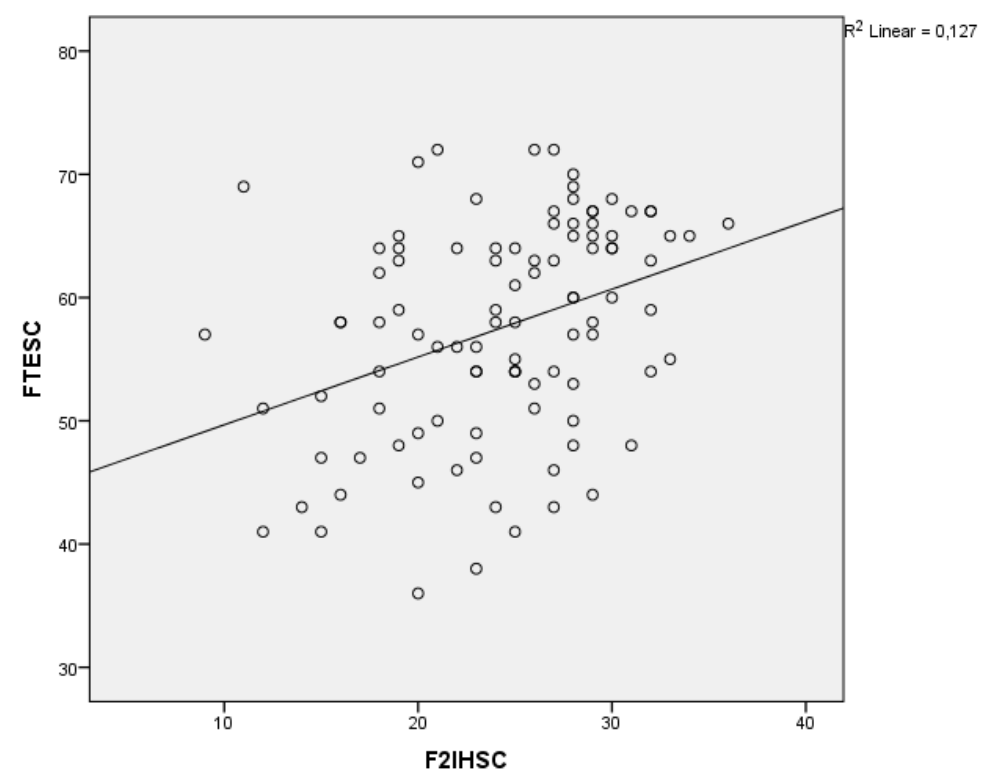

D- Diagrama de dispersão mostrando a correlação entre o F5 do IHSC e o escore total da ESC $(n=100 ; r=0,409 ; \mathrm{p}<0001)$

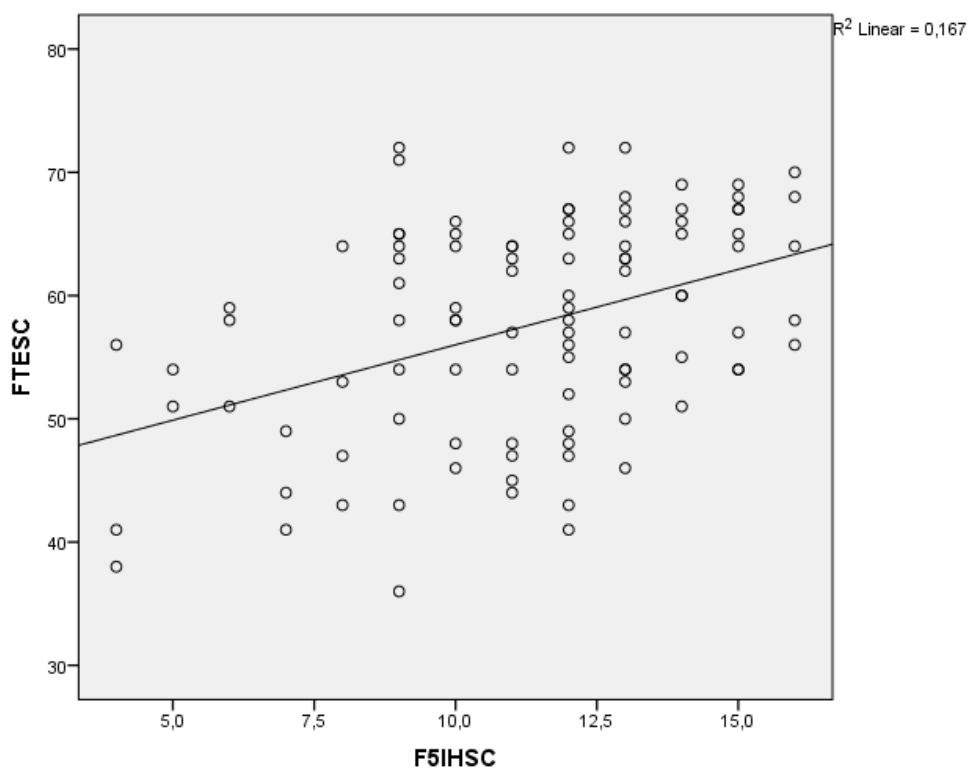

E- Diagrama de dispersão mostrando a correlação entre o escore do QEC e o escore total da $\operatorname{ESC}(\mathrm{n}=100 ; \mathrm{r}=0 ; 611 ; \mathrm{p}<0001)$

\section{POLÊM!CA $\mid$ LABORE}




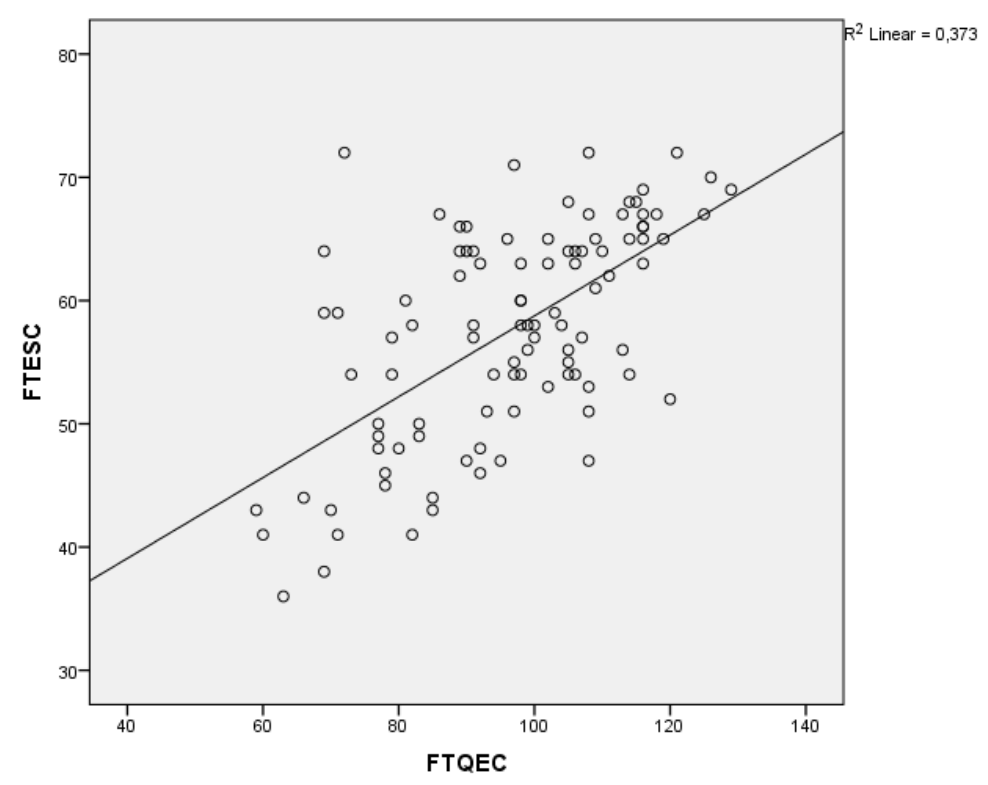

Apesar de haver correlação entre as medidas, elas não apresentaram a mesma intensidade, de acordo com classificação proposta por Dancey e Reidy (2013). Todas as correlações foram consideradas moderadas, com exceção daquela existente entre o F2 do IHSC e o fator total da ESC, como podemos observar na Tabela 4.

Tabela - 4: Correlação entre o escore total da ESC e F1, F2, F5, fator total do IHSC e o fator total do QEC

\begin{tabular}{lccc}
\hline & & FT ESC & \\
& $r$ & $p<$ & intensidade \\
\hline IHSC & & \\
F1 & 0,581 & 0,000 & Moderada positiva \\
F2 & 0,356 & 0,000 & Fraca positiva \\
F5 & 0,409 & 0,000 & Moderada positiva \\
FT & 0,696 & 0,000 & Moderada positiva \\
QEC & & & \\
FT & 0,611 & 0,000 & Moderada positiva
\end{tabular}

FT ESC = Escore total da Escala de Satisfação Conjugal; IHSC = Inventário de Habilidades Sociais Conjugais; F1 = Expressividade e empatia; F2 Autoafirmação assertiva; F5 = Conversação assertiva; FT = Fator total do Inventário de Habilidades Sociais Conjugais; QEC = Questionário de Empatia Conjugal; FT = Fator total do Questionário de Empatia Conjugal ${ }^{*} \mathrm{p}<0,05 ;{ }^{* *} \mathrm{p}=0,001 ; * * * \mathrm{p}<0,001$

\section{POLÊM!CA $\mid$ LABORE}


A partir dos dados obtidos, podemos observar a correlação positiva entre a empatia percebida pelo cônjuge e a satisfação conjugal. Compreendendo um pouco mais a correlação entre as duas medidas para empatia (Fator 1 Expressividade/Empatia do IHSC e o fator total do QEC) e a satisfação conjugal (fator total do ESC), podemos afirmar que o r de 0,6, nas duas medidas, mostrou que 36\% da variância de satisfação conjugal é explicada pela variância da habilidade empática do cônjuge. O nível de probabilidade associado de 0,001 mostrou que é improvável que esse resultado tenha ocorrido apenas ao acaso.

Quando verificamos as variáveis relacionadas à comunicação assertiva do cônjuge (F2 Autoafirmação assertiva e F5 Conversação assertiva do IHSC), observamos associação, mas em menor intensidade. Para cada uma das variáveis, o $\mathrm{r}$ de 0,4 deixa claro que $16 \%$ da variância da satisfação conjugal é explicada pela variância da autoafirmação assertiva (F2) e conversação assertiva (F5) do cônjuge. Novamente com o nível de probabilidade associado de 0,001 .

Merece também destaque o fato de que $49 \%$ da variância da satisfação conjugal (fator total da ESC) é explicada pela variância das habilidades sociais do cônjuge (fator total de IHSC), com nível de probabilidade associado de 0,001.

Estes resultados corroboram dados da literatura que apontam para uma associação entre as habilidades sociais do (a) parceiro (a) e a satisfação conjugal. Destas habilidades, a empatia mostra uma associação mais intensa, quando comparamos à comunicação assertiva.

\section{Discussão}

Os casais entrevistados não apresentaram diferenças estatisticamente significativas na satisfação conjugal. Também não observamos diferenças na habilidade empática, bem como na autoafirmação assertiva. Dos fatores diretamente analisados, a única diferença, apontando um melhor desempenho para as mulheres, foi na conversação assertiva. As mulheres da nossa amostra tinham maior habilidade para expor suas opiniões, defendendo-as, sabendo, ao mesmo tempo, respeitar as opiniões de seus esposos. Apesar de não ter sido uma variável diretamente analisada neste estudo, cabe apresentar o dado de que as mulheres, segundo seus esposos, também apresentavam melhor habilidade em se preocupar com o outro, conforme podemos observar na análise do FATOR CAE do QEC.

A satisfação conjugal, conforme nos mostra a literatura, é um construto ainda em discussão. O fato de ser um conceito subjetivo aumenta a dificuldade para sua conceituação,

\section{POLÊM!CA $\mid$ LABORE}


pois cada pessoa avalia a seu modo sobre o que considera ou não ser satisfatório na relação conjugal (FÉRES-CARNEIRO \& MOSMANN, 2006).

Estudos recentes apontam para o papel das habilidades sociais na satisfação conjugal. Elas podem ser consideradas como um elemento fundamental para a qualidade das relações interpessoais. Alguns autores têm destacado o fato de que as habilidades podem tornar as pessoas mais satisfeitas em suas relações conjugais (FIGUEREDO, 2005).

Dentre as habilidades sociais descritas, destacamos como objeto deste estudo a empatia e a comunicação assertiva.

Nesta pesquisa procuramos investigar se as habilidades sociais empatia e comunicação assertiva, percebidas pelo cônjuge, mostram-se relacionadas com a satisfação conjugal, conforme tem sido apontado na literatura, comparando o papel de cada uma. Contudo, diferente dos demais estudos, este teve como participantes casais. É importante ressaltar que não trabalhamos com uma amostra representativa da população casada, mas com uma amostra não-probabilista intencional. Esta técnica de composição da amostra é adequada para os interesses do estudo, ou seja, compreender o papel da empatia e da comunicação assertiva na satisfação conjugal.

Ponderando que neste estudo um dos objetivos era averiguar o papel da empatia na satisfação do casamento, verificamos que existe uma correlação positiva e significativa entre satisfação conjugal e empatia percebida pelo cônjuge. Corroboramos, portanto, com Sardinha, Falcone e Ferreira (2009) quando afirmam que a empatia exerce uma grande influencia na qualidade da relação conjugal.

O indivíduo que tem um parceiro (a) empático (a) tende a relatar maior satisfação conjugal. A presença de empatia proporcionará condições para tornar as relações mais prazerosas, evitando ocorrências de brigas e separações. É por meio da habilidade empática do parceiro que o indivíduo se sente compreendido, tendo os seus sentimentos devidamente validados e acolhidos (FALCONE, 1999; VILLA, 2005).

Quando o cônjuge busca ver os acontecimentos sob o olhar do outro, muitos atritos conseguem ser evitados, comprovando dessa maneira a importância da comunicação empática na interação. A forma como o casal manifesta seus sentimentos e opiniões irá refletir na satisfação com o casamento (FIGUEREDO, 2005). Portanto, uma pessoa empática com seu parceiro, conforme descrevem Oliveira, Falcone e Ribas (2009), certamente procurará entender as razões e diferenças de seu companheiro (a), ouvindo com atenção e sensibilidade.

\section{POLÊM!CA | LABORÉ}

Polêmica - Revista Eletrônica da Uerj - Rua São Francisco Xavier, 524, $1^{\circ}$ andar bloco D, sl.1001 • Tels.: +55 21 2334-4088 / 4087 • http://www.e-publicacoes.uerj.br/index.php/polemica/index http://www.labore.uerj.br • laboreuerj@yahoo.com.br 
Dessa forma, como afirmam Sardinha, Falcone e Ferreira (2009), quanto maior for o grau da empatia percebido pelo cônjuge, melhor será a interação do casal e maiores serão também os níveis de satisfação alcançados nos aspectos emocionais e estruturais.

Os dados desta pesquisa indicam ainda que o casal com capacidade de manifestar seus sentimentos contribui mutuamente para maior satisfação no casamento, o que justifica nosso interesse pela habilidade de comunicação assertiva, apesar deste fator influenciar a satisfação conjugal em menor intensidade do que a empatia.

A literatura nos mostra que, habitualmente, expressar de maneira assertiva anseios, sentimentos e necessidades contribuem para melhor solucionar problemas interpessoais, sendo algo importante para a vida conjugal, aumentando o senso de autoeficácia e a autoajuda, melhorando a qualidade da relação e gerando tranquilidade (FALCONE, 1999).

Muitas vezes, de acordo com Tanganelli (2003), quando as dificuldades aparecem no momento de entender o comportamento e sentimentos do cônjuge, pode o relacionamento fracassar. Desse modo, expressar sentimentos e opiniões, de maneira correta, contribui para que o outro atenda suas necessidades de maneira mais positiva. Ser compreendido e acolhido de maneira empática provoca um sentimento de aceitação e valorização, aumentando a satisfação de um indivíduo no casamento. Do mesmo modo, o parceiro que consegue de maneira adequada manifestar seus sentimentos, possivelmente se sentirá mais feliz ao promover bem-estar ao seu cônjuge.

Portanto, segundo Falcone (2003), a pessoa assertiva consegue lidar melhor com as situações de conflito, pois desenvolvendo essa habilidade fica mais atenta às suas necessidades e direitos, reconhecendo ao mesmo tempo os direitos do outro. É importante destacar, contudo, que somente uma correta expressão de sentimentos e opiniões do indivíduo não constitui uma relação interpessoal satisfatória; ele necessita ainda da empatia para elevar a qualidade do seu relacionamento.

No presente estudo verificamos que a correlação entre a comunicação assertiva e a satisfação conjugal ocorre, contudo, a sua intensidade é menor do que com a habilidade empática. Aparentemente, uma conduta interessante seria investir na capacidade de comunicação empática, para posteriormente enfatizar a comunicação assertiva.

Esta direção nos faz lembrar da técnica “A crítica em forma de sanduíche” apresentada por Caballo (1996). Neste procedimento é sugerido que uma crítica seja colocada no meio de duas mensagens positivas, facilitando a sua escuta e compreensão. O mesmo podemos falar da

\section{POLÊM!CA $\mid$ LABORE}

Polêmica - Revista Eletrônica da Uerj - Rua São Francisco Xavier, 524, $1^{\circ}$ andar

bloco D, sl.1001 • Tels.: +55 21 2334-4088 / 4087 • http://www.e-publicacoes.uerj.br/index.php/polemica/index http://www.labore.uerj.br • laboreuerj@yahoo.com.br 
habilidade empática e a comunicação assertiva, quando sugerimos que a empatia facilitaria a comunicação assertiva entre os casais.

O estudo, portanto, corrobora pesquisas anteriores que comprovam ser a satisfação conjugal influenciada pelo elevado nível das habilidades empáticas e assertivas, sendo que com a empatia a correlação é mais intensa. Nossa expectativa é que esses resultados possam contribuir para a compreensão das variáveis que influenciam na satisfação conjugal.

\section{Conclusões}

Avaliar e desenvolver as habilidades sociais nos casais é uma conduta importante para a melhoria da satisfação conjugal. Das habilidades investigadas, a empatia se apresenta como de elevada importância para a promoção de relacionamentos conjugais mais satisfatórios. A capacidade de comunicação assertiva não deve ser desconsiderada, já que há correlação com a satisfação conjugal, contudo esta é menos intensa.

Acrescentamos, também, que pesquisas longitudinais seriam indicadas para uma maior compreensão do desenvolvimento destes fenômenos.

\section{Referências}

ALBERT, R. E., \& EMMONS, M. L. Comportamento Assertivo: Um guia de auto expressão. Belo Horizonte: Interlivros, 1978.

CABALLO, V. E. O treinamento em habilidades sociais. In: CABALLO, V. E. (Org.). Manual de técnicas de terapia e modificação do comportamento. São Paulo: Editora Santos, p. 361-398, 1996.

DANCEY, C. P., \& REIDY, J. Estatística sem matemática para psicologia. Porto Alegre: Penso, 2013.

DATTILIO, F. M. Manual de Terapia Cognitivo-Comportamental para Casais e Família. Porto Alegre: Artmed, 2011.

DEL PRETTE, A., \& DEL PRETTE, Z. A. Psicologia das habilidades sociais: Terapia e Educação. Petrópolis: Vozes, 1999.

Psicologia das relações interpessoais: vivências para o trabalho em grupo. Petrópolis: Vozes, 2001.

DEL PRETTE, Z. A., VILlA, M. B., FREITAS, M. G., \& DEL PRETTE, A. A Estabilidade temporal do Inventário de Habilidades Sociais Conjugais (IHSC). Avaliação Psicológica, v. 7, n.1, p. 67-74, 2008.

DELA COLETA, M. F. A medida da satisfação conjugal: adaptação de uma escala. Psico, v. 2, p. 90-112, 1989.

ELIAS, P. V. O., \& BRITTO, I. A. G. S. A função da assertividade no relacionamento afetivo. In: STARLING, R. R. (Org.). Sobre Comportamento e Cognição: temas aplicados, vol.19, Santo André: ESETec, p.23-36, 2007.

\section{POLÊM!CA $\mid$ LABORE}


FALCONE, E. M. O. A avaliação de um programa de treinamento de empatia com universitários. Revista Brasileira de Terapia Comportamental Cognitiva, v. 1, p. 23-32, 1999.

. Não sei o que fazer ou dizer quando alguém me critica. In: LIPP, M. (Org.). O stress está dentro de você. São Paulo: Contexto, p.76-85, 2003.

FALCONE, E. M. O., FERREIRA, M. C., LUZ, R. C. M., FERNANDES, C. S., FARIA, C. A., D’AUGUSTIN, J. F., SARDINHA, A., \& PINHO, V. D. Inventário de Empatia (IE): Desenvolvimento e validação de uma medida brasileira. Revista Avaliação Psicológica, v. 7, p. 321-334, 2008.

FÉRES-CARNEIRO, T. Casamento contemporâneo: o difícil convívio da individualidade com a conjugalidade. Psicologia Reflexão e Crítica, v.11, n.2, 1998.

FÉRES-CARNEIRO, T., \& MOSMANN, C. Qualidade Conjugal: Mapeando Conceitos. Paidéia, v. 16, n. 15, p. 315-325, 2006.

FIGUEREDO, P. M. A influência do lócus de controle conjugal, das habilidades sociais conjugais e da comunicação conjugal na satisfação com o casamento. Ciências \& Cognição, ano 2, v.6, 2005.

MALAMUT, G. Satisfação Conjugal e empatia auto-percebida e percebida pelo cônjuge. Anais do II Seminário Internacional de Habilidades Sociais. Rio de Janeiro: UERJ, 2009.

MOSMANN, C., \& FALCKE, D. Conflitos conjugais: motivos e frequência. Revista SPAGESP, v.12, n.2, p. 516, 2011.

MOSMANN, C., WAGNER, A., \& FÉRES-CARNEIRO, T. Qualidade Conjugal: mapeando conceitos. Paidéia, v. 16, n. 35, p. 315-325, 2006.

NORGREN, M. B. P., SOUZA, M. R., KASLOW, F., HANMERSCHMIDT, H., \& SARLIN, S. A. Satisfação Conjugal em casamento de longa duração: uma construção possível? Estudos de Psicologia, v. 9, p. 575-584, 2004.

OLIVEIRA, M. G. S., FALCONE, E. M. O., \& RIBAS, R. C. A avaliação das relações entre a empatia e a satisfação conjugal: um estudo preliminar. Interação, v. 13, 2009.

SARDINHA, A., FALCONE, E. M. O., \& FERREIRA, M. C. (2009). As relações entre Satisfação Conjugal e as Habilidades Sociais percebidas no cônjuge. Psicologia: Teoria e Pesquisa, jul-Set, v.25, n.3, p. 395-402, 2009.

TANGANELLI, M. S. Você me estressa, eu estresso você. In: LIPP, M. (Org.). O stress está dentro de você. São Paulo: Contexto, p.155-168, 2003.

VICENTE, C. C., MENDES, D. M. L. F., \& PESSOA, L. F. Habilidades Sociais nascem no berço. Anais do II Seminário Internacional de Habilidades Sociais. Rio de Janeiro: UERJ, p. 15, 2009.

VILLA, M. B. Habilidades sociais no casamento: avaliação e contribuição para a satisfação conjugal. Ribeirão Preto. 121 p. Tese (Doutorado) - Faculdade de Filosofia, Ciência e Letras de Ribeirão Preto / USP. Departamento de Psicologia. Orientador: DEL PRETTE, Zilda Aparecida Pereira, 2005.

VILLA, M. B., \& DEL PRETTE, Z. A. Inventário de habilidades sociais conjugais (IHSC): manual de aplicação, apuração e interpretação. São Paulo: Casa do Psicólogo, 2012.

WENDLING, M. I. O casamento na Contemporaneidade: Construindo Espaços para o Eu e o Nós na Relação. Pensando Famílias, v.11, n. 1, p. 87-105, 2007.

Recebido em: 17/09/2015.

Aceito em: 06/04/2016.

\section{POLÊM!CA $\mid$ LABORE}

Polêmica - Revista Eletrônica da Uerj - Rua São Francisco Xavier, 524, $1^{\circ}$ andar

bloco D, sl.1001 • Tels.: +55 21 2334-4088 / 4087 • http://www.e-publicacoes.uerj.br/index.php/polemica/index

http://www.labore.uerj.br • laboreuerj@yahoo.com.br 


\section{POLÊM!CA $\mid$ LABORE}

Polêmica - Revista Eletrônica da Uerj - Rua São Francisco Xavier, 524, $1^{\circ}$ andar bloco D, sl.1001 • Tels.: +55 $212334-4088$ / 4087 • http://www.e-publicacoes.uerj.br/index.php/polemica/index http://www.labore.uerj.br • laboreuerj@yahoo.com.br 